\title{
Evaluation of the Biocontrol Potential of Some Medicinal Plant Materials Alone and in Combination with Trichoderma harzianum Against Rhizoctonia solani AG 2-1
}

\author{
Hye Min Lee', Zakaullah Khan², Sang Gyu Kim', Nam-In Baek ${ }^{3}$ and Young Ho Kim ${ }^{1 *}$ \\ ${ }^{1}$ Department of Agricultural Biotechnology and Center for Agricultural Biomaterials, Seoul National University, Seoul 151-921, \\ Korea \\ ${ }^{2}$ Division of Germplasm Evaluation, National Bureau of Plant Genetic Resources, New Delhi -110 012, India \\ ${ }^{3}$ Graduate School of Biotechnology \& Institute of Life Sciences \& Resources, Kyung Hee University, Yongin 446-701, Korea \\ (Received on December 8, 2010; Accepted on February 4, 2011)
}

Fifty five species of medicinal plant materials were tested for their antifungal activity in vitro against Rhizoctonia solani AG 2-1 and Trichoderma harzianum to select plant species that can be used to improve the biocontrol efficacy of $T$. harzianum. Six species were effective against $R$. solani AG 2-1 but were also antagonistic to $T$. harzianum, except for Cinnamomum loureirii stem bark (CSB). CSB inhibited mycelial growth of $R$. solani AG 2-1 by 73.7\% but showed an inhibitory effect on mycelial growth of $T$. harzianum by only $2.2 \%$. Scanning electron microscophs showed that the CSB treatment resulted in deformed $R$. solani AG 2-1 hyphal cells, and transmission electron microscophs revealed degenerated cell structures such as degenerated cytoplasm and disentangled cell wall and the accumulation of electron-dense inclusions (asterisks) in the CSB treatment. The biocontrol efficacy of radish damping-off increased greatly following the combined treatments of T. harzianum and CSB and the combined treatment increased efficacy from $6.4-23.1 \%$ to $37.1-87.3 \%$ compared with either treatment alone. CSB did not affect $T$. harzianum population growth, as it was almost the same in rice-bran peat medium (culture) amended with $0.1 \%$ and $1.0 \%$ CSB powder as in non-amended medium. The formulation of $T$. harzianum in rice-bran peat medium amended with CSB powder reduced the severity of radish damping-off by $80.6 \%$, suggesting that $T$. harzianum and CSB can be formulated as a biocontrol product for the control of $R$. solani AG 2-1.

Keywords : Biocontrol, Cinnamomum loureirii stem bark, Rhizoctonia solani, Trichoderma harzianum

Rhizoctonia solani Kühn is a fungal pathogen causing damping-off in several crops under both greenhouse and open field conditions (Berta et al., 2005). Managing

\footnotetext{
*Corresponding author.

Phone) +82-2-880-4675, FAX) +82-2-873-2317

E-mail)yhokim@snu.ac.kr
}

Rhizoctonia damping-off mainly relies on the use of chemicals, but the overuse of chemical fungicides leads to adverse impacts on the environment, humans, and animal health and induces a pathogenic resistance to chemicals. These issues and a means to develop eco-friendly and safer control methods have encouraged research efforts aimed at finding new and effective methods for controlling plant diseases. Emerging strategies for plant disease management involve biological and integrated control by applying antagonistic microorganisms alone or in combination with and/or alternating with fungicides or natural materials (Lima and De Cicco, 2006; Paulitz and Belanger, 2001). Biological control appears to offer an environmentally safe and economically feasible strategy for plant protection and has great potential to promote sustainable agriculture. However, although numerous microorganisms have been considered potential agents for suppressing plant pathogens, only a few have been commercialized (Brannen and Kenney, 1997; Gerhardson, 2002).

Trichoderma harzianum is a filamentous soil fungus that functions as a biocontrol agent for a wide range of economically important plant pathogens (Chet, 1987; Papavizas, 1985). Trichoderma spp. are worldwide in occurrence and easily isolated from soil, decaying wood, and other forms of plant organic matter (Howell, 2003). The potential of Trichoderma spp. as biocontrol agents of plant diseases was first recognized in the early 1930s (Weindling, 1932), and subsequently, control of many diseases has been added to the list (Harman, 2000). Trichoderma strains have been used against Rhizoctonia solani on several crops (Elad et al., 1981; Lee et al., 2008; Lewis et al., 1998; Ruppel et al., 1983). Trichoderma produces a large range of secondary metabolites with inhibitory traits, including direct mycoparasitism as well as lysis and degradation of the cell wall by enzymes (Howell, 2003). The mycoparasitic activity of this organism is attributable to a combination of successful nutrient competition (Brannen and Kenney, 1997), production of cell wall-degrading enzymes (Pierson and Weller, 1994), and antibiosis (Hjelord and Tronsmo, 
1998; Nandakumar et al., 2001). Several strains of Trichoderma have been tested as an alternative to chemical fungicides (Howell, 1998). However, achieving full disease control in soil is difficult mainly because of the complexity of the plant-soil system, whereby the microbial inoculum is affected by biotic and abiotic factors and shows relatively lower efficacies compared to those of applying chemicals under various environmental conditions. Therefore, the integrated use of microorganisms and chemical pesticides and/or natural materials may be an effective method applicable in the field. Using mixtures or combinations of biological agents may improve biological control, particularly when they exhibit different or complementary modes of action. Combined applications of a biocontrol agent and synthetic chemicals or plant materials often provide better plant protection than individual treatments (Bardin et al., 2003; Duffy, 2000). The combined application of Paeonia suffruticosa cortex (medicinal plant) and T. harzianum is more effective than either treatment alone for controlling Rhizoctonia damping-off (Lee, 2005; Lee et al., 2008). A combined application of metalaxyl with either $T$. harzianum or Pseudomonas cepacia resulted in lower disease incidences of red pepper phytophthora blight than by any single treatment (Kim et al., 1991). Two different biocontrol agents used in a mixture of Pichia guilliermondii and Bacillus mycoides are higher in control efficacy than that achieved by separate inoculation, and the variability of suppression was reduced (Guetsky et al., 2001, 2002).

The antimicrobial activity of plant materials and their extracts have been recognized for many years. In particular, the antimicrobial activities of plant materials and essential oils have formed the basis of preservation, pharmaceutical, alternative medicine, and natural therapies (Lis-Balchin and Deans, 1997; Reynolds, 1996). Natural plant materials are possible sources of environmentally friendly agrochemicals that are effective against pathogens (Zaika, 1988). In this study, we conducted an in vitro screening of antifungal medicinal plant materials antagonistic to $R$. solani AG 2-1 but not to $T$. harzianum to select potential plant materials useful for controlling the pathogen with the biocontrol agent in combination. The efficacies of individual and combined treatments of antifungal plant materials and the biocontrol agent, T. harzianum, were evaluated for the control of radish damping-off of $R$. solani AG 2-1 under greenhouse conditions.

\section{Materials and Methods}

Source of fungal inoculums and preparation of fungal culture. $R$. solani AG 2-1 was obtained from KT\&G Central Research Institute, Suwon, Korea. The biocontrol organism, T. harzianum, was isolated from soil and main- tained at the Department of Agricultural Biotechnology, Seoul National University, Seoul, Korea, and used for artificial inoculations. A pure mycelia culture generated through a single spore of this isolate, maintained in potatodextrose agar (PDA; Difco Laboratories, Detroit, MI, USA) at $28^{\circ} \mathrm{C}$, served as an initial inoculum source. For the mass culture, both fungi were grown in potato-dextrose broth (PDB; Alpha Biosciences, Baltimore, MD, USA) at $25^{\circ} \mathrm{C}$ for 2 weeks.

Screening of medicinal plant extracts for their antifungal activity. Fifty-five dried medicinal plant materials were collected from Kyung-Dong Mart, Seoul, Korea, to test their antifungal activity against $R$. solani $\mathrm{AG} 2-1$ and $T$. harzianum. They were one species each in 21 familes including Alismataceae, Cornaceae, Cyperaceae, Discoreaceae, Eucommiaceae, Lardizabalaceae, Lobeliaceae, Magnoliaceae, Oleaceae, Orobanchaceae, Pinaceae, Polygalaceae, Rhamnaceae, Rosaceae, Rubiaceae, Sapindaceae, Schisandraceae, Scrophulariaceae, Solanaceae, Umbelliferae, and Zingiberaceae; four species including Angelica gigas root in Apiaceae, four including Atractylodes macrocephala root in Asteraceae; three including Adenophora verticillata root in Campanulaceae; and the other 23 species in Fabaceae (4), Labiatae (2), Lauraceae (3), Myrtaceae (3), Paeoniaceae (2), Polyporaceae (6), and Rutaceae (3). The collected medicinal plant materials were washed in sterilized distilled water and air-dried, then $10 \mathrm{~g}$ of each plant material was ground separately in an electric grinder (Alozen; Alona Electronic Co. Ltd., Daejon, Korea) and extracted in $20 \mathrm{ml}$ of ethanol overnight. The resultant solution was passed through filter paper (grade 3 qualitative, $150 \mathrm{~mm}$ diameter; Whatman, Kent, UK), which were used to test the antifungal efficacy on $R$. solani AG 2-1 and T. harzianum. For this, 8-mm-diameter paper disks (Toyo Roshi Kaisha, Ltd., Tokyo, Japan) were soaked with $50 \mu 1$ of each ethanol extract, dried under ultraviolet light, and placed on PDA plates aseptically under laminar flow $3 \mathrm{~cm}$ away from the fungi. Paper disks soaking in absolute ethanol served as the control. Four days later, $R$. solani AG 2-1 and T. harzianum mycelial growth was examined and antagonistic potentials of plant extracts were calculated as given below:

$$
\mathrm{I}=(\mathrm{C}-\mathrm{T}) / \mathrm{C} \times 100,
$$

where $\mathrm{I}$ is the percent inhibition in mycelial growth, $\mathrm{C}$ is the growth of mycelium in the control $(\mathrm{mm})$, and $\mathrm{T}$ is the growth of the mycelium in the treatment (mm). Each experiment was performed with five replicates.

Efficacy of the selected medicinal plant extracts on mycelial growth. Fifty-five medicinal plant materials were tested for their antifungal potential; six showed moderate to 
strong antifungal activity against $R$. solani AG 2-1 but were not so antagonistic to T. harzianum in a preliminary study. These selected medicinal plant materials were Cinnamomum loureirii stem bark (CSB), Eugenia caryophyllata flower bud (Bud Clove, EFB), Zanthoxylum piperitum fruit (Fructus Zanthoxyli, ZF), Curcuma aromatica rhizome (Rhizobium Curcumae aromatase, CR) and Polygala tenuifolia rhizome (Radix Polygalae, PR). For each, $10 \mathrm{~g}$ of dried material was extracted in $100 \mathrm{ml}$ ethanol as described in the above section and fully dried using a rotary vacuum evaporator (Rotavapor R-200; Büchi, Flawil, Switzerland) under reduced pressure at $37^{\circ} \mathrm{C}$. The extracted residue was dissolved again in $10 \mathrm{ml}$ of ethanol, which was considered a standard solution. For further dilution, $1 \mathrm{ml}$ of standard ethanol extracts was added separately to $100 \mathrm{ml}$ melted PDA aseptically, under laminar flow, and mixed thoroughly to obtain a $1 \%$ concentration of the amendments. The amended medium was poured onto sterilized Petri dishes under laminar flow and allowed to solidify. Each plate was inoculated with 2$\mathrm{mm}$ disks of a mycelial bit taken from the periphery of a 7day-old colony of $R$. solani AG 2-1 and T. harzianum, then placed $3 \mathrm{~cm}$ away from one another and incubated at $25^{\circ} \mathrm{C}$. Mycelial growth of $R$. solani AG 2-1 and T. harzianum was measured after a 4-day incubation. Medium without medicinal plant extracts served as a control. The synergistic effect of T. harzianum and the medicinal plant materials on the growth of $R$. solani AG 2-1 was measured by comparing the mycelial growth of the pathogen and the antagonistic fungus on the media incorporated with and without medicinal plant extracts. Each experiment was performed with five replicates.

Effect of a combined treatment of T. harzianum and medicinal plant materials on $R$. solani AG 2-1 mycelial growth. The synergistic effect of $T$. harzianum and the two plant materials, FEB and CSB, on $R$. solani AG2-1 mycelial growth was investigated by coculturing the pathogen with T. harzianum on PDA amended with various concentrations of plant material ethanol extracts (Table 2). To obtain the desired concentrations of amendment, the required amounts of plant extracts were added to the PDA as described in the previous section.

Antagonistic actions of $T$. harzianum on $R$. solani AG 21. The two fungi were cocultured on glucose agar (water agar containing $0.5 \%$ glucose) to observe the antagonistic action of T. harzianum on R. solani AG 2-1. After a 24-h incubation, when the T. harzianum mycelia grew over (interacted with) the $R$. solani AG 2-1 mycelia, samples containing the interacting mycelial zones were observed by scanning electron microscopy (SEM). For SEM, agar disks
(1 mm thick) were cut from interacting zones of $T$. harzianum and $R$. solani AG 2-1 on glucose agar and prepared for SEM observation as described below. Agar disks were fixed at $4{ }^{\circ} \mathrm{C}$ in modified Karnovsky's fixative consisting of 5\% paraformaldehyde and 5\% glutaraldehyde in $0.2 \mathrm{M}$ phosphate buffer ( $\mathrm{pH} 7.2$ ) for $4 \mathrm{~h}$. The fixed samples were washed with $0.2 \mathrm{M}$ phosphate buffer three times for $15 \mathrm{~min}$ per wash. The samples were post-fixed again in $2 \%$ osmium tetroxide $\left(\mathrm{OsO}_{4}\right)$ in $0.2 \mathrm{M}$ phosphate buffer ( $\mathrm{pH} 7.2$ ) at $4{ }^{\circ} \mathrm{C}$ for $4 \mathrm{~h}$. The samples were washed again with $0.1 \mathrm{M}$ phosphate buffer solution three times for 15 min per wash and then dehydrated in an ethanol series $(30 \%, 50 \%, 70 \%, 80 \%, 90 \%$, and $100 \%)$ for $15 \mathrm{~min}$ at each concentration. The final exposure to $100 \%$ ethanol was repeated three times. The specimens were critical-point dried, sputter-coated with gold using a sputter coater (JFC1110E; JEOL, Tokyo, Japan) and observed under SEM (JSM-5410LV; JEOL) at $20 \mathrm{kV}$.

\section{Antifungal activity of the CSB extract against $\boldsymbol{R}$. solani}

AG 2-1. To observe the antifungal activity of the CSB extract against $R$. solani AG 2-1, $R$. solani AG 2-1 fungal disks were incubated on PDA plates with a paper disk $(8$ $\mathrm{mm}$ diameter) soaked in CSB ethanol extract. A paper disk soaked in absolute ethanol was used as the control. An inhibition zone formed around the CSB-treated paper disk; agar disks (1 mm thick) were cut from the interaction zone of the fungal colony and prepared for SEM observations as described in above section. The samples were also observed under transmission electron microscopy (TEM). For this, agar disks were fixed with modified Karnovsky's fixative consisting of $2 \%(\mathrm{v} / \mathrm{v})$ glutaraldehyde and $2 \%(\mathrm{v} / \mathrm{v})$ paraformaldehyde in $0.05 \mathrm{M}$ sodium cacodylate buffer $(\mathrm{pH} 7.2)$ at $4{ }^{\circ} \mathrm{C}$ overnight and washed with the same buffer three times for $10 \mathrm{~min}$ each. The specimens were post-fixed with $1 \%(\mathrm{w} / \mathrm{v}) \mathrm{OsO}_{4}$ in the same buffer at $4{ }^{\circ} \mathrm{C}$ for $2 \mathrm{~h}$ and washed with distilled water two times briefly. The postfixed specimens were en bloc stained in $0.5 \%(\mathrm{w} / \mathrm{v})$ uranyl acetate at $4{ }^{\circ} \mathrm{C}$ overnight. They were dehydrated in a graded ethanol series for $10 \mathrm{~min}$ each as described above, and the final exposure to $100 \%$ ethanol was repeated three times. The samples were further treated with propylene oxide as a transition fluid twice for $15 \mathrm{~min}$ each and embedded in Spurr's epoxy resin. The embedded samples were sectioned (80-90 nm thick) with a glass knife on an ultramicrotome (MT-X; RMC, Inc., Tucson, AZ, USA). Sections were mounted on copper grids and stained with $2 \%$ uranyl acetate and lead citrate for $10 \mathrm{~min}$ each and observed under TEM (JEM-1010; JEOL) at 80 kV. Electron micrographs were recorded and digitized using an image processing system (FDL 5000; Fuji Photo Film Ltd.). 
Antifungal activity of combined treatments of $T$. harzianum and CSB ethanol extract on $R$. solani AG 2-1. The pathogen and $T$. harzianum were cocultured on PDA containing $0.1 \% \mathrm{CSB}$ ethanol extract to observe the synergistic effect of T. harzianum and CSB ethanol extract on $R$. solani AG 2-1. The interacting zones between $T$. harzianum and $R$. solani AG 2-1 on PDA were cut and prepared for SEM observation as described in earlier sections.

\section{Effect of medicinal plant materials on Rhizoctonia radish} damping-off. Radish seeds (Raphanus sativus L.) cv. Guem-jung, obtained from Kyungshin seeds Co. Ltd., Seoul, Korea, were sown in 10-cm diameter plastic pots containing a soil mixture (organic matter:sand:soil $=1: 1: 1$ ) that had been autoclaved twice at $121^{\circ} \mathrm{C}$ for $1 \mathrm{~h}$ on 2 consecutive days. For pathogen inoculation, $R$. solani AG 2-1 was cultured in oatmeal-sand medium (consisting of sand, oatmeal powder, and moisture in the ratio of 20:1:4, v/v) at $25^{\circ} \mathrm{C}$ for 2 weeks, and then incorporated into sterilized soil mixture at a 0.03 ratio (w/w) 2 days before seed sowing. The medicinal plant materials, EFB and CSB, which were ground to a powder, were added to the soil mixture at the rate of $0.1 \%, 0.2 \%, 0.4 \%, 0.6 \%, 0.8 \%$, and $1.2 \%(\mathrm{w} / \mathrm{w}) 2$ days before seed sowing. Prior to sowing, radish seeds were surface-sterilized in 1\% NaOCl (Ducksan, Seoul, Korea) for $1 \mathrm{~min}$ and rinsed three times in sterilized distilled water. Ten seeds were sown into each container with five replicates for each treatment. Untreated pots served as controls. The plants were maintained in a greenhouse at room temperature and watered daily to field capacity. The occurrence of pre- and post-emergence damping-off was examined at 7 days after planting.

Effect of various components of $T$. harzianum on $R$ hizoctonia radish damping-off. $R$. solani AG 2-1 inoculum was prepared as described above and used as the pathogen to evaluate the control effect of various $T$. harzianum components on radish damping-off. The biocontrol agent, T. harzianum, was cultured in PDB at $25^{\circ} \mathrm{C}$ for 2 weeks. The mycelial masses were saved by carefully draining the culture filtrates from the fungal cultures. The separated mycelial masses and drained T. harzianum culture filtrates were applied to the soil 2 days before seed sowing as follows: a $1.0 \%(\mathrm{w} / \mathrm{w})$ mycelial mass with $10 \mathrm{ml}$ of culture medium, $1.0 \%(\mathrm{w} / \mathrm{w})$ mycelial mass washed in sterilized distilled water, and $10 \mathrm{ml}$ of $T$. harzianum culture filtrate, and all of these treatments were followed by heat treatment at $100{ }^{\circ} \mathrm{C}$ for $1 \mathrm{~h}$. Ten seeds were sown into the pots with five replicates for each treatment. The plants were maintained in a greenhouse at room temperature and watered daily to field capacity. The occurrence of pre- and postemergence damping-offs was examined at 7 days after planting.
Table 1. Inhibitory effect of selected medicinal plant materials on mycelial growth of Rhizoctonia solani AG 2-1 and Trichoderma harzianum

\begin{tabular}{|c|c|c|c|c|}
\hline \multirow{2}{*}{$\begin{array}{l}\text { Medicinal } \\
\text { plant } \\
\text { materials }^{\mathrm{a}}\end{array}$} & \multicolumn{2}{|c|}{ R. solani AG 2-1 } & \multicolumn{2}{|c|}{ T. harzianum } \\
\hline & $\begin{array}{l}\text { Mycelial } \\
\text { growth } \\
(\mathrm{cm})\end{array}$ & $\begin{array}{c}\text { Mycelial } \\
\text { inhibition } \\
(\%)\end{array}$ & $\begin{array}{l}\text { Mycelial } \\
\text { growth } \\
(\mathrm{cm})\end{array}$ & $\begin{array}{c}\text { Mycelial } \\
\text { inhibition } \\
(\%)\end{array}$ \\
\hline EFB & $1.0 \pm 0.1$ & 73.7 & $3.2 \pm 0.2$ & 28.9 \\
\hline CSB & $1.1 \pm 0.1$ & 71.1 & $4.4 \pm 0.1$ & 2.2 \\
\hline $\mathrm{ZF}$ & $1.4 \pm 0.2$ & 63.2 & $3.3 \pm 0.5$ & 26.7 \\
\hline $\mathrm{CR}$ & $2.3 \pm 0.1$ & 39.5 & $3.2 \pm 0.5$ & 28.9 \\
\hline PR & $2.5 \pm 0.7$ & 34.2 & $3.9 \pm 0.3$ & 13.3 \\
\hline MSB & $2.8 \pm 0.1$ & 26.3 & $2.2 \pm 0.1$ & 51.5 \\
\hline Control $^{\mathrm{b}}$ & $3.8 \pm 0.2$ & - & $4.5 \pm 0.1$ & - \\
\hline
\end{tabular}

${ }^{a}$ EFB (Eugenia caryophyllata flower bud), CSB (Cinnamomum loureirii stem bark), ZF (Zanthoxylum piperitum fruit), CR (Curcuma aromatica rhizome), PR (Polygala tenuifolia rhizome), MSB (Machilus thunbergii stem bark)

${ }^{\mathrm{b}}$ Control (soaked with absolute ethanol and dried)

Table 2. Synergistic effect of medicinal plant materials and Trichoderma harzianum on mycelial growth of Rhizoctonia solani AG 2-1

\begin{tabular}{ccccc}
\hline \hline \multirow{2}{*}{$\begin{array}{c}\text { Treatment } \\
\text { conc. } \\
(\mathrm{v} / \mathrm{v} \%)^{\mathrm{a}}\end{array}$} & \multicolumn{3}{c}{ Mycelial growth of R. solani AG 2-1 (cm) } \\
\cline { 2 - 5 } & \multicolumn{2}{c}{ EFB $^{\mathrm{b}}$} & \multicolumn{2}{c}{ CSB } \\
\hline 1.00 & $0.0 \pm 0.0$ & $0.0 \pm 0.0$ & $0.0 \pm 0.0$ & $0.0 \pm 0.0$ \\
0.10 & $0.6 \pm 0.1$ & $0.5 \pm 0.1$ & $2.1 \pm 0.2$ & $1.1 \pm 0.2$ \\
0.01 & $2.2 \pm 0.1$ & $2.0 \pm 0.2$ & $2.3 \pm 0.2$ & $1.1 \pm 0.1$ \\
0.00 & $3.5 \pm 0.1$ & $2.9 \pm 0.5$ & $3.6 \pm 0.1$ & $2.9 \pm 0.6$ \\
\hline
\end{tabular}

${ }^{a}$ Ethanol extracts of medicinal plant materials added to potato dextrose agar (PDA) at various concentrations.

${ }^{\mathrm{b}}$ EFB (Eugenia caryophyllata), CSB (Cinnamomum loureirii).

${ }^{\mathrm{c}}$ Mycelial growth of $R$. solani AG 2-1 cultured with TH (T. harzianum) or without TH on PDA containing ethanol extracts of plant materials

Effect of individual and combined treatments of CSB powder and T. harzianum on Rhizoctonia radish damping-off. In vitro experiments have shown that CSB extracts do not inhibit $T$. harzianum mycelial growth (Table 1) but that their combined application enhances the inhibition of $R$. solani AG 2-1 mycelia growth compared to an individual application (Table 2). Therefore, an attempt was made to evaluate the biocontrol potential of CSB powder and T. harzianum as individual agents or in combination against Rhizoctonia radish damping-off in potted soil. $R$. solani AG 2-1 inoculum was prepared and incorporated in potted soil as described above. Mycelia of T. harzianum cultured on PDB at $25^{\circ} \mathrm{C}$ for 15 days were harvested and partially dried for $1 \mathrm{~h}$ at room temperature to prepare biocontrol agent inocula. T. harzianum and the CSB powder 
were added to the potted soil alone or in combination at various dose concentrations (Table 5). Radish seeds were surface-sterilized in $1 \% \mathrm{NaOCl}$ for $1 \mathrm{~min}$ and rinsed three times in sterilized distilled water. Ten seeds were sown into each container with five replicates for each treatment. Untreated pots served as controls. The plants were maintained in a greenhouse at room temperature and watered daily to field capacity. The occurrence of pre- and postemergence damping-off was examined at 7 days after planting.

Effect of CSB amendments on growth of T. harzianum in rice-bran peat medium. CSB powder was added to the autoclaved rice-bran peat medium (consisting of peat, rice bran, and moisture in a ratio of $8: 2: 4, \mathrm{v} / \mathrm{v} / \mathrm{v}$ ) at the rate of $1.0 \%$ and $0.1 \%(\mathrm{w} / \mathrm{v})$ and mixed thoroughly. Prepared media were inoculated with $5 \mathrm{ml}$ of $1.0 \times 10^{3} / \mathrm{ml}$ spore suspension of $T$. harzianum and incubated at $25^{\circ} \mathrm{C}$ in an incubator. The population of T. harzianum was observed on $5,7,14,18$, and 24 days post inoculation with CSB powder. For this, $1 \mathrm{~g}$ of $T$. harzianum inoculated medium was taken and dissolved in $9 \mathrm{ml}$ of distilled water, serially diluted, and spread on Trichoderma selective medium (TSM medium containing $0.2 \mathrm{~g} \mathrm{MgSO}_{4} \cdot 7 \mathrm{H}_{2} \mathrm{O}, 0.9 \mathrm{~g} \mathrm{~K}_{2} \mathrm{HPO}_{4}, 1.0 \mathrm{~g} \mathrm{NH}_{4} \mathrm{NO}_{3}$, $0.15 \mathrm{~g} \mathrm{KCl}, 0.15 \mathrm{~g}$ rose bengal, $3 \mathrm{~g}$ glucose, and $20 \mathrm{~g}$ agar per liter of distilled water, after autoclave sterilization, and $0.25 \mathrm{~g}$ chloramphenicol, $90 \mathrm{mg}$ streptomycin, $0.2 \mathrm{~g}$ quintozene were added) (Askew, 1993). The colony-forming units (CFU) for each treatment on the selective medium were examined 2 days after incubation.

Effect of formulated T. harzianum in rice-bran peat medium amended with CSB on radish damping-off. To evaluate the efficacy of the formulated T. harzianum in rice bran on Rhizoctonia damping-off of radish, T. harzianum was cultured for 14 days at room temperature in rice-bran peat medium containing $1.0 \%, 0.1 \%$, and $0.0 \%(\mathrm{w} / \mathrm{w} / \mathrm{w})$ CSB powder. The $R$. solani AG 2-1 inoculum was prepared as described above and the formulated T. harzianum was added to potted soil at a rate of $0.1 \%(\mathrm{w} / \mathrm{w}) 2$ days before seed sowing. Ten seeds were sown into each pot with five replicates for each treatment. The plants were maintained in a greenhouse at room temperature and watered daily to field capacity. The occurrence of pre- and post-emergence damping-off was examined at 7 days after planting.

Statistical analysis. Data from repeated experiments were analyzed by two-way analysis of variance performed on the data followed by Duncan's multiple range test to compare between treatments at $P \leq 0.05$. All statistical analyses were done using Analyse-it software for Excel (Microsoft, Redmond, WA, USA). No significant differences were observed between the repeated experiments, and thus data from duplicate tests were pooled for analysis.

\section{Results}

Screening of antifungal materials against $R$. solani AG 2-1. Fifty five medicinal plant materials were tested for their antifungal activity against $R$. solani AG 2-1 and $T$. harzianum. No significant reduction in mycelial growth of $R$. solani was noted by most medicinal materials tested (data not shown), except for six medicinal plant materials including CSB, EFB, PR, CR, ZF, and Machilus thunbergii stem bark (Cortex Manoliae, MSB; Table 1). These plant materials had significantly inhibited mycelia growth of the biocontrol agent, $T$. harzianum $(P \leq 0.05)$, except CSB, which inhibited mycelial growth of $T$. harzianum by only $2.2 \%$. Among these six medicinal plant materials, EFB and CSB were the most effective against $R$. solani AG 2-1 mycelial growth, revealing an inhibitory efficacy of $73.7 \%$ and $71.1 \%$, respectively, compared to untreated controls.

Effect of combined treatment of medicinal plant materials and T. harzianum on mycelial growth of $R$. solani AG 21. The synergistic effect of $T$. harzianum and the two most effective medicinal plant materials, FEB and CSB, against $R$. solani AG 2-1 was investigated by coculturing the pathogen, $R$. solani AG 2-1, with $T$. harzianum on PDA amended separately with FEB and CSB. The inhibition of $R$. solani AG 2-1 mycelial growth was significantly enhanced on the PDA amended with CSB compared to non-amended media at all concentrations tested, except $1.0 \%$, at which no fungal growth was observed (Table 2). In contrast, the combined treatment of $T$. harzianum and FEB did not enhance the inhibition of mycelial growth compared to either treatment alone $(P \leq 0.05)$.

Interactions between T. harzianum and $R$. solani AG 21. SEM revealed that the T. harzianum hyphae grew along and over $R$. solani AG 2-1, frequently branching and coiling around the host hyphae (Fig. 1A, B). The main hyphae of $T$. harzianum coiled around the host ( $R$. solani AG 2-1) and produced short branches that tightly surrounded the host hyphae. The detached T. harzianum hyphae revealed a hole in the host cell wall and the $T$. harzianum hyphae were growing inside the host hyphae (Fig. 1B).

Inhibitory effect of CSB ethanol extracts on $R$. solani AG 2-1. The SEM observation of the $R$. solani AG 2-1 untreated control showed smooth, straight, and normally growing hyphae (Fig. 2A), whereas the pathogen hyphae treated with CSB ethanol extracts showed a knotty-look with distorted hyphae and local swelling on hyphal tips and 


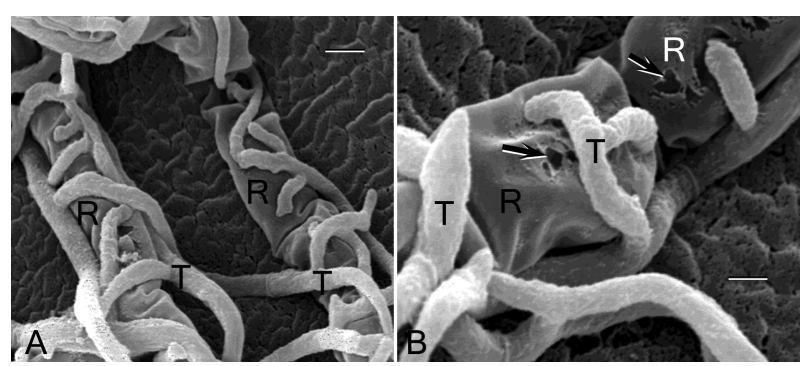

Fig. 1. Scanning electron micrographs showing interactions between Trichoderma harzianum (T) and Rhizoctonia solani AG 2-1 (R). T. harzianum coiling around $R$. solani AG 2-1 hyphae (A) and detached hyphae of $T$. harzianum revealing a hole in an $R$. solani AG 2-1 cell (arrow). Bars $=10 \mu \mathrm{m}$.

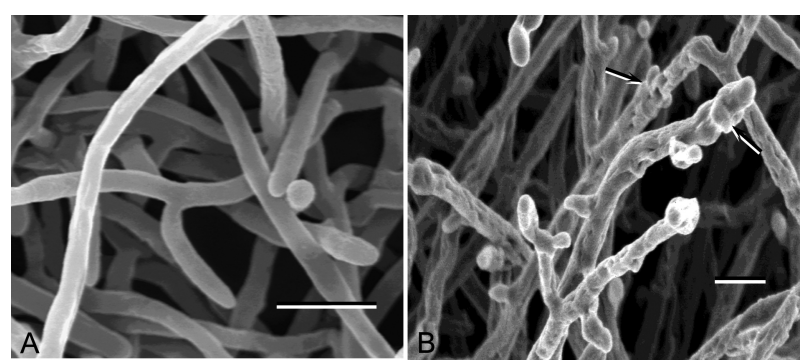

Fig. 2. Scanning electron micrographs showing inhibited growth of Rhizoctonia solani AG 2-1 hyphae caused by Cinnamomum loureirii stem bark (CSB) ethanol extracts. A: Control, smooth, straight and normally-growing hyphae; B: Treated with CSB ethanol extracts, showing knotty and distorted hyphae with local swelling (arrow) on hyphal tips and interhyphal cells. Bars $=20$ $\mu \mathrm{m}$.

inter-hyphal cells (Fig. 2B). The TEM structural features of $R$. solani AG 2-1 without CSB treatment were normallooking with a dolipore septum (with glucan deposits), vacuoles, vesicles, and intact organelles such as mitochondria and paramural bodies, whereas the cytoplasm of the pathogen-infested hyphal cells was degenerated with an occasional accumulation of electron-dense inclusion bodies (Fig. 3). Cell wall degradation was noted in the $R$. solani AG 2-1 hyphal cells treated with CSB, which was indicated by the disentangled outer layer of hyphal cells (Fig. 3C). The morphological features of the fungal hyphae treated with CSB indicated that it inhibited hyphal growth.

Effect of a combined treatment of CSB and T. harzianum on $R$. solani AG 2-1 mycelial growth. SEM on $R$. solani AG 2-1 treated with CSB ethanol extract and $T$. harzianum in combination revealed severely distorted and destroyed hyphae, which were coiled by T. harzianum (Fig. 4A). The severely distorted pathogen hyphal cells were penetrated by $T$. harzianum hyphae, indicating hyperparasitism (Fig. 4B).

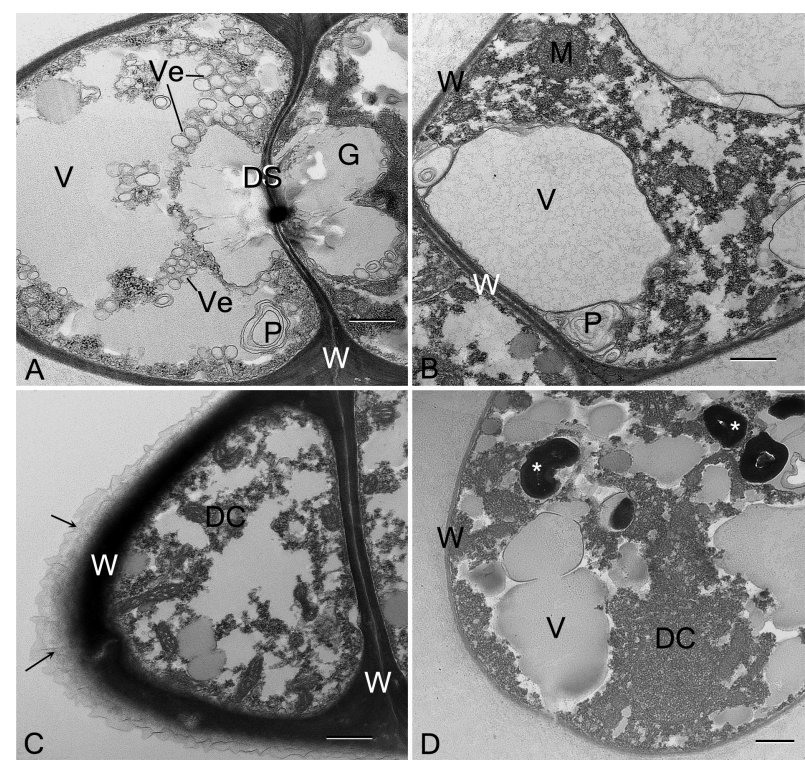

Fig. 3. Transmission electron micrographs of Rhizoctonia solani AG 2-1 hyphae, showing intact cell structures such as the cell wall (W), dolipore septum (DS) with deposit of glucan (G), vacuoles $(\mathrm{V})$, vesicles $(\mathrm{Ve})$, and paramural bodies $(\mathrm{P})$ in the control (A, B), and degenerated cell structures such as degenerated cytoplasm (DC) and disentangled cell wall (arrow, W) and the accumulation of electron-dense inclusions (asterisks) in the Cinnamomum loureirii stem bark $(\mathrm{CSB})$ treatment $(\mathrm{C}, \mathrm{D})$. Bars $=$ $0.5 \mu \mathrm{m}$.

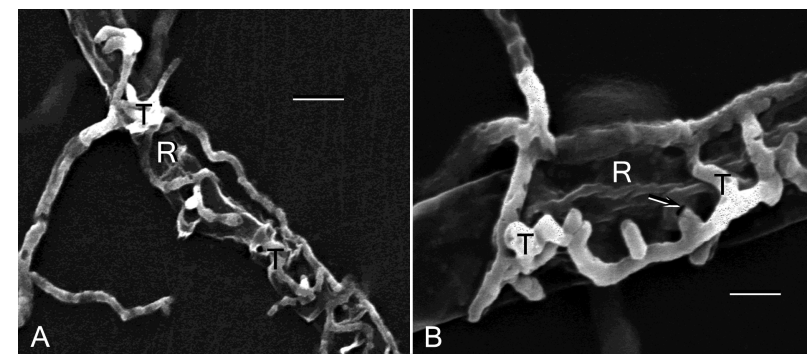

Fig. 4. Scanning electron micrographs showing interactions between Trichoderma harzianum (T) and Rhizoctonia solani AG 2-1 (R) on medium amended with Cinnamomum loureirii stem bark (CSB), showing $T$. harzianum coiling around severely distorted $R$. solani AG 2-1 hyphae (A) and penetrating the T. harzianum hypha in a $R$. solani AG 2-1 cell (arrow) (B). Bars $=20 \mu \mathrm{m}$.

Effect of EFB and CSB amendments on Rhizoctonia radish damping-off. Soil amendments with EFB and CSB at various concentrations significantly reduced the incidence of Rhizoctonia damping-off of radish (Table 3). The control effect increased with increasing application concentrations. The highest control effect $(90.9 \%)$ of EFB powder was recorded when applied at a rate of $0.8 \%$ and $1.2 \%(\mathrm{w} / \mathrm{w})$. However, the control effect decreased to $54.5 \%$ when applied at the lowest concentration of $0.1 \%$. Applying CSB 
Table 3. Effect of various doses of medicinal plant materials (EFB and CSB) on Rhizoctonia damping-off of radish

\begin{tabular}{ccccc}
\hline \hline \multirow{2}{*}{\begin{tabular}{c} 
Treatment $\begin{array}{c}\text { conc. } \\
(\% \mathrm{w} / \mathrm{w})^{\mathrm{a}}\end{array}$ \\
\cline { 2 - 5 }
\end{tabular}} & $\begin{array}{c}\text { EFB treatment } \\
\text { incidence } \\
(\%)\end{array}$ & $\begin{array}{c}\text { Control } \\
\text { effect } \\
(\%)\end{array}$ & $\begin{array}{c}\text { Disease } \\
\text { incidence } \\
(\%)\end{array}$ & $\begin{array}{c}\text { Control } \\
\text { effect } \\
(\%)\end{array}$ \\
\hline 0.0 & $76.7 \mathrm{dc}$ & 0.0 & $70.5 \mathrm{f}$ & 0.0 \\
0.1 & $34.9 \mathrm{c}$ & 54.5 & $54.5 \mathrm{de}$ & 22.7 \\
0.2 & $23.3 \mathrm{bc}$ & 69.6 & $50.0 \mathrm{cde}$ & 29.1 \\
0.4 & $14.0 \mathrm{ab}$ & 81.8 & $45.5 \mathrm{bcd}$ & 35.5 \\
0.6 & $9.3 \mathrm{ab}$ & 87.9 & $38.6 \mathrm{bc}$ & 45.3 \\
0.8 & $7.0 \mathrm{a}$ & 90.9 & $36.4 \mathrm{~b}$ & 48.4 \\
1.2 & $7.0 \mathrm{a}$ & 90.9 & $36.0 \mathrm{~b}$ & 48.9 \\
Control & $0.0 \mathrm{a}$ & - & $0.0 \mathrm{a}$ & -
\end{tabular}

${ }^{\mathrm{a}}$ Concentrations of medicinal plant materials amended in soil.

${ }^{\mathrm{b}} \mathrm{EFB}$ (Eugenia caryophyllata powder), CSB (Cinnamomum loureirii powder).

${ }^{\mathrm{C}}$ Means within columns followed by the same letters are not significantly different by Duncan's multiple range test at $P=0.05$.

Table 4. Effect of various components of Trichoderma harzianum on Rhizoctonia damping-off of radish

\begin{tabular}{llcc}
\hline \hline & Treatments $^{\mathrm{a}}$ & $\begin{array}{c}\text { Disease } \\
\text { incidence }(\%)\end{array}$ & $\begin{array}{c}\text { Control effect } \\
(\%)\end{array}$ \\
\hline Without & TH culture & $38.8 \mathrm{c}^{\mathrm{b}}$ & 55.1 \\
heat treat- & TH culture filtrate & $44.1 \mathrm{c}$ & 49.0 \\
ment & TH washed mycelium & $17.8 \mathrm{~b}$ & 79.4 \\
With heat & TH culture & $72.7 \mathrm{de}$ & 15.9 \\
treatment & TH culture filtrate & $65.9 \mathrm{~d}$ & 23.8 \\
& TH washed mycelium & $70.5 \mathrm{~d}$ & 18.5 \\
& RS & $86.4 \mathrm{e}$ & 0.0 \\
& Control & $0.0 \mathrm{a}$ & - \\
\hline
\end{tabular}

${ }^{\mathrm{a}} \mathrm{RS}$ (inoculated with $R$. solani AG 2-1 at 3\% (w/w)), control (uninoculated)

${ }^{b}$ Means followed by the same letters within the column are not significantly different at $P=0.05$ by Duncan's multiple range test. TH, Trichoderma harzianum

was less effective than applying EFB, as the highest control value of CSB was $48.9 \%$ at an application concentration of $1.2 \%$. The control efficiency of CSB also increased significantly with the increase of dose concentration up to certain level $(0.8 \%)$ (Table 3$)$. However, soil amendments with CSB at a rate of $1.2 \%$ showed adverse effects on radish growth, including much reduced plant height and weight compared to uninoculated controls (data not shown).

Effect of various components of T. harzianum on radish damping-off. Radish damping-off was suppressed by all of the $T$. harzianum components used (Table 4). However, the highest disease suppression was achieved in pots treated with the washed mycelia of $T$. harzianum with its control
Table 5. Effect of individual and combined treatments of Trichoderma harzianum and Cinnamomum loureirii on Rhizoctonia damping-off of radish

\begin{tabular}{cccc}
\hline \hline \multicolumn{2}{c}{ Treatments $^{\mathrm{a}}$} & $\begin{array}{c}\text { Disease incidence } \\
(\%)\end{array}$ & $\begin{array}{c}\text { Control effect } \\
(\%)\end{array}$ \\
\cline { 1 - 2 } CSB (\%) & TH (\%) & $95.9 \mathrm{e}^{\mathrm{b}}$ & 0.0 \\
0.0 & 0.0 & $89.8 \mathrm{e}$ & 6.4 \\
& 0.3 & $74.3 \mathrm{c}$ & 22.5 \\
0.05 & 0.6 & $87.8 \mathrm{e}$ & 8.4 \\
& 0.0 & $54.3 \mathrm{~cd}$ & 37.1 \\
& 0.3 & $41.2 \mathrm{c}$ & 57.0 \\
0.1 & 0.6 & $73.7 \mathrm{de}$ & 23.1 \\
& 0.0 & $40.1 \mathrm{c}$ & 58.2 \\
& 0.3 & $12.5 \mathrm{~b}$ & 87.3 \\
& 0.6 & $0.0 \mathrm{a}$ & -
\end{tabular}

${ }^{\mathrm{a}}$ Treatment with CSB (Cinnamomum loureirii) powder and TH (T. harzianum) at various concentrations in potted soil.

${ }^{\mathrm{b}}$ Means within columns followed by the same letters are not significantly different at $P=0.05$ by Duncan's multiple range test.

effect of $79.4 \%$, whereas applying mycelia plus culture medium and its culture filtrate suppressed disease incidence moderately with control effects of $55.1 \%$ and $49.0 \%$, respectively. When the washed mycelia of $T$. harzianum and other materials were heat-treated, their control efficacy decreased drastically to between $15.9 \%$ and $23.8 \%$, indicating that the antagonistic activity of $T$. harzianum may be related to biological factors.

Effect of individual and combined treatments of CSB and T. harzianum on radish damping-off. Applying CSB and $T$. harzianum individually or in combination reduced the severity of radish damping-off caused by $R$. solani AG 2-1 at all doses tested, but was more effective when two were combined than when either treatment was used alone (Table 5). When CSB and T. harzianum were applied separately at dose concentrations of $0.05-0.1 \%$ and $0.3-$ $0.6 \%(\mathrm{~W} / \mathrm{W})$, it resulted in $8.4-23.1 \%$ and $6.4-22.5 \%$ disease control, respectively. In contrast, the combined treatments of CSB powder and T. harzianum at various dose concentrations greatly increased the control efficacy, with disease control values of 37.1-87.3\%.

Effect of the CSB amendment on T. harzianum growth in rice-bran peat medium. The population of $T$. harzianum in rice-bran peat medium with or without CSB powder grew continuously until 24 days after inoculation (Fig. 5). The $T$. harzianum populations at 5 days after inoculation were 4.5, 4.6, and $4.6 \log \mathrm{CFU} / \mathrm{g}$ medium containing CSB powder at a rate of $1.0 \%, 0.1 \%$, and $0.0 \%$ (control), respectively, showing that population growth of T. harzianum in 


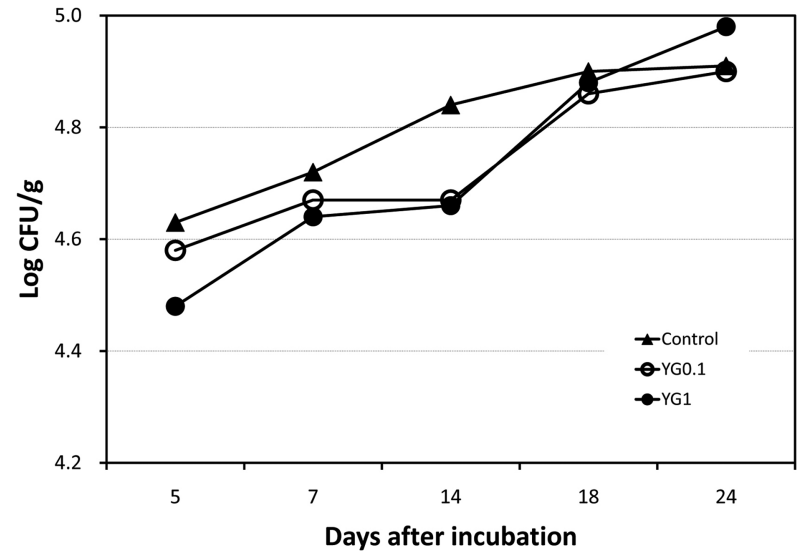

Fig. 5. Effect of Cinnamomum loureirii stem bark (CSB) amendment doses $(\mathrm{YG} 1=1 \% \mathrm{CSB}$ powder, $\mathrm{YG} 0.1=0.1 \% \mathrm{CSB}$ powder $)$ on growth of Trichoderma harziamum in rice-bran peat medium.

Table 6. Effect of formulated Trichoderma harzianum in peat medium on Rhizoctonia damping-off of radish

\begin{tabular}{lcc}
\hline \hline Treatment $^{\mathrm{a}}$ & Disease incidence (\%) & Control effect (\%) \\
\hline Control & $0.0 \mathrm{a}^{\mathrm{b}}$ & - \\
$\mathrm{RS}$ & $100.0 \mathrm{~d}$ & 0.0 \\
Peat & $100.0 \mathrm{~d}$ & 0.0 \\
$\mathrm{TH}+0.00 \% \mathrm{CSB}$ & $77.1 \mathrm{c}$ & 22.9 \\
$\mathrm{TH}+0.01 \% \mathrm{CSB}$ & $47.5 \mathrm{~b}$ & 52.5 \\
$\mathrm{TH}+0.1 \% \mathrm{CSB}$ & $19.4 \mathrm{~b}$ & 80.6
\end{tabular}

${ }^{\mathrm{a}}$ Control (uninoculated), RS (inoculated with $R$. solani AG 2-1 only at a 0.03 ratio, w/w); peat $(0.1 \%(\mathrm{w} / \mathrm{w})$ peat powder only), TH (T. harzianum cultured for 14 days in rice-bran peat medium amended with $0.0 \%, 0.01 \%$, and $0.1 \%(\mathrm{w} / \mathrm{w})$ CSB powder).

${ }^{\mathrm{b}}$ Means followed by the same letters within the column are not significantly different at $P=0.05$ by Duncan's multiple range test.

rice-bran peat medium was not affected by the CSB amendment at the tested concentrations (Fig. 5).

Effect of a formulated biocontrol agent on radish damping-off. $T$. harzianum in rice-bran peat medium amended with CSB powder efficiently reduced disease severity of Rhizoctonia radish damping-off. T. harzianum culture without a CSB amendment had a control effect of $22.9 \%$, but the control effect increased to $52.5 \%$ and $80.6 \%$ after adding $0.05 \%$ and $0.1 \% \mathrm{CSB}$ to the $T$. harzianum treatments, respectively (Table 6).

\section{Discussion}

Among the 55 medicinal plant materials tested for antifungal activity against $R$. solani AG 2-1, six of them, namely CSB, EFB, PR, CR, ZF, and MSB, had moderate to strong antifungal activity against $R$. solani AG 2-1. In particular, EFB and CSB were highly antagonistic toward
$R$. solani AG 2-1, but EFB also inhibited mycelia growth of T. harzianum significantly. This antifungal nature of the plant materials was more antagonistic to the pathogen than to the biocontrol agent, which may have enhanced control efficacy when these materials were applied together with the biocontrol agent for pathogen control. The antifungal activity of E. caryophyllata essential oil has been demonstrated on several food-borne fungi (Lopez et al., 2005; Ranasinghe et al., 2002; Velluti et al., 2004), and one of its ingredient, eugenol, displays acaricidal activity against Dermatophagoides spp. (Kim et al., 2003; Lee and Kim, 2006). CSB has shown antifungal activity against Alternaria alternata (Kim et al., 1996) and acaricidal activity against Dermatophagoides spp. (Kim, 2002). Its antimicrobial and antifungal properties have drawn great attention from several researchers (Cheng et al., 2006; Kim et al., 2004; Lee et al., 2005), but so far, no synergistic effects of these materials with microbial biocontrol agents had been examined.

The synergistic effect of antifungal activity was tested with a combined treatment of $T$. harzianum and EFB or $\mathrm{CSB}$ in an in vitro system. The combined treatment of EFB and $T$. harzianum did not effectively enhance the control efficacy of Rhizoctonia damping-off of radish, compared to the use of either treatment alone. In contrast, control efficacy was greatly enhanced by the combined treatment of CSB and T. harzianum in various concentrations, compared to the use of either treatment alone. The combined treatment of CSB and T. harzianum enhanced the control efficacy more than the sum of single treatments alone in pot experiments, and compared to the combined treatments of FEB and T. harzianum, probably because of large differential antibiosis. CSB may also enhance the competitiveness of the biocontrol agent over the pathogen, thus increasing control efficacy due to the differential antibiosis.

The CSB ethanol extract induced hyphal swelling and rugged morphology of $R$. solani AG 2-1 hyphal cells, of which the mode of action may involve the release of volatile antimicrobial substances such as cinnamaldehyde (Kim et al., 1996). T. harzianum hyphae grew along those of $R$. solani AG 2-1 and formed branches that coiled around and penetrated the pathogen hyphal cells. Considering these microscopic aspects and that the control efficacy of $T$. harzianum mycelia washed in distilled water to remove antibiotic substances was the highest among all treatments, the major mode of action for controlling $R$. solani AG 2-1 may be mycoparasitism. Mycoparasitism is the chief mechanism for the biocontrol of Sclerotinia sclerotiorum by $T$. harzianum (Jacob et al., 1996). The major mode of action for the combined treatment activity of CSB and $T$. harzianum may involve severe destruction of pathogen hyphae by the initial antagonistic effect of CSB and the subsequent hyperparasitism of $T$. harzianum, which may 
further damage and weaken hyphae. Because of these synergistic effects in addition to the differential antibiosis, combined treatments may further enhance the efficacy of controlling $R$. solani AG 2-1 than either single treatment alone.

The amendment of $1.0 \%(\mathrm{w} / \mathrm{w})$ CSB powder in rice-bran peat medium did not inhibit the T. harzianum growth rate as compared to the control medium without CSB powder. Furthermore, this formulation significantly enhanced control efficacy. These results suggest that CSB can be added to proper media to mass produce the biocontrol agent, which can be directly used to produce the biocontrol formulation and be applied to the soil without an additional CSB amendment to improve control efficacy. This biocontrol method would reduce the amount of biocontrol agent needed and increase the convenience of application.

\section{Acknowledgments}

This study was conducted with the support of the "Research Cooperating Program for Agricultural Science \& Technology Development (Project No. OA-20060501036009)," RDA, Republic of Korea.

\section{References}

Bardin, S. D., Huang, H. C. and Koyer, J. R. 2003. Control of Pythium damping off of sugar beet by seed treatment with crop straw powders and a biocontrol agent. Biol. Contr. 4:1-8.

Berta, G., Sampo, S., Gamalero, E., Massa, N. and Lemanceau, P. 2005. Suppression of Rhizoctonia root-rot of tomato by Glomus mossae BEG12 and Pseudomonas fluorescens A6RI is associated with their effect on the pathogen growth and on the root morphogenesis. Eur. J. Plant Pathol. 111:279-288.

Brannen, P. M. and Kenney, D. S. 1997. Kodiak-a successful biological control product for suppression of soil-borne plant pathogens of cotton. J. Industr. Microbiol. Biotechnol. 19:169-171.

Cheng, S. S., Liu, J. Y., Hsui, Y. R. and Chang, S. T. 2006. Chemical polymorphism and antifungal activity of essential oils from leaves of different provenances of indigenous cinnamon (Cinnamomum osmophloeum). Biores. Technol. 97:306-312.

Chet, I. 1987. Trichoderma: Application, mode of action and potential as a biocontrol agent of soilborne plant pathogenic fungi. In: Innovative approaches to plant disease control, ed. by I. Chet, pp. 137-160. Wiley \& Sons, New York, USA.

Duffy, B. 2000. Combinations of pencycuron and Pseudomonas fluorescens strain 2-79 for integrated control of Rhizoctonia root rot and take all of spring wheat. Crop Prot. 19:21-25.

Elad, Y., Chet, I. and Henis, Y. 1981. Biological control of Rhizoctonia solani in strawberry fields by Trichoderma harzianum. Plant Soil 60:245-254.

Gerhardson, B. 2002. Biological substitute for pesticides. Trends Biotechnol. 20:338-343.
Guetsky, R., Shtienberg, D., Elad, Y. and Dinnor, A. 2001. Combining biocontrol agents to reduce the variability of biological control. Phytopathology 91:621-627.

Guetsky, R., Shtienberg, D., Elad, Y., Fischer, E. and Dinnor, A. 2002. Improving biological control by combining biocontrol agents each with several mechanisms of disease suppression. Phytopathology 92:976-985.

Harman, G. E. 2000. Myths and dogmas of biocontrol: Changes in oriented derived from research on Trichoderma harziamum T22. Plant Dis. 84:377-393.

Hjelord, L. and Tronsmo, A. 1998. Trichoderma and Gliocladium in biological control: An overview. In: Trichoderma and Gliocladium, Vol. 2. Enzymes, biological control and commercial application, ed. by GE. Harman and C.P. Hubicek, pp. 129 151. Taylor and Francis Ltd., London, UK.

Howell, C. R. 1998. The role of antibiosis in biocontrol. In: Trichoderma and Gliocladium, Vol. 2. Enzymes, biological control and commercial application, ed. by G.E. Harman and C.P. Hubicek, pp. 173-183. Taylor and Francis Ltd., London, UK.

Howell, C. R. 2003. Mechanisms employed by Trichoderma species in the biological control of plant disease: The history and evolution of current concepts. Plant Dis. 87:4-10.

Jacob, I., Ana, M. and Ilan, C. 1996. Hyphal interaction between Trichoderma harzianum and Sclerotinia sclerotiorum and its role in biological control. Soil Biol. Biochem. 28:757-763.

Kim, E. H. 2002. Acaricidal activity of phenylpropenes identified from essential oil of Eugenia caryophyllata against Dermatophagoides farinae, Dermatophagoides pteronyssinus (Acari; Pyroglyphidae) and Tyrophagus putrescentiae (Acari; Acaridae), Graduate School of Seoul National University, Korea.

Kim, E. H., Kim, H. K. and Ahn, Y. J. 2003. Acaricidal activity of clove bud oil compounds against Dermatophagoides farina and Dermatophagoides pteronyssinus (Acari: Pyroglyphidae). J. Agric. Food Chem. 51:885-889.

Kim, H. K., Kim, K. D. and Jee, H. J. 1991. Enhanced suppression of red-pepper Phytophthora blight by combined applications of antagonist and fungicide. Korean J. Plant Pathol. 7:221-225.

Kim, H. O., Park, S. W. and Park, H. D. 2004. Inactivation of Escherichia coli $\mathrm{O} 157: \mathrm{H} 7$ by cinnamic aldehyde purified from Cinnamomum cassia shoot. Food Microbiol. 21:105110.

Kim, Y. H., Yu, Y. H. and Oh, S. H. 1996. Screening of antagonistic natural materials against Alternaria alternata. Korean $J$. Plant Pathol. 12:68-71.

Lee, H. C. and Kim, I. S. 2006. Acaricidal effects of herb essential oils against Dermatophagoides farinae and D. pteronyssinus (Acari: Pyroglyphidae) and qualitative analysis of a herb Mentha pulegium (pennyroyal). Korean J. Parasitiol. 44:133-138.

Lee, H. C., Cheng, S. S. and Chang, S. T. 2005. Antifungal property of the essential oils and their constituents from Cinnamon osmophloeum leaf against tree pathogenic fungi. J. Sci. Food Agric. 85:2047-2053.

Lee, T. O. 2005. Biological control of soilborne disease using antagonistic organisms and natural materials. Graduate School 
of Seoul National University, Korea.

Lee, T. O., Khan, Z., Kim, S. G. and Kim, Y. H. 2008. Amendment with peony root bark improves the biocontrol efficacy of Trichoderma harzianum against Rhizoctonia solani. J. Microbiol. Biotechnol. 18:1537-1543.

Lewis, Y., Larkin, R. P. and Roger, D. L. 1998. A formulation of Trichoderma and Gliocladium to reduce damping off caused by Rhizoctonia solani and saprophytic growth of the pathogen in soilless mix. Plant Dis. 82:501-506.

Lima, G and De Cicco, V. 2006. Integrated strategies to enhance biological control of postharvest diseases. In: Advances in post-harvest technology for horticultural crops, Vol. 1, ed. by N. Benkeblia and N. Shiomi, pp. 173-194. Research Signpost, Kerala, India.

Lis-Balchin, M. and Deans, S. G. 1997. Bioactivity of selected plant essential oils against Listerria monocytogenes. J. Appl. Bacteriol. 82:759-762.

Lopez, P., Sanchez, C., Batlle, R. and Nerin, C. 2005. Solid- and vapor-phase antimicrobial activities of six essential oils: Susceptibility of selected foodborne bacterial and fungal strains. $J$. Agric. Food Chem. 53:6939-6946.

Nandakumar, R., Babu, S., Viswanathan, R., Sheela, J., Raguchander, T. and Samiyappan, R. 2001. A bioformulation containing plant growth promoting rhizobacterial mixtures for the management of sheath blight and enhanced grain yield in rice. Biocontrol 46:493-510.

Papavizas, G C. 1985. Trichoderma and Gliocladium: Biology, ecology and potential for biocontrol. Annu. Rev. Phytopathol.
23:23-54.

Paulitz, T. C. and Belanger, R. R. 2001. Biological control in greenhouse system. Annu. Rev. Phytopathol. 39:25-33.

Pierson, E. A. and Weller, D. M. 1994. Use of mixtures of fluorescent pseudomonads to suppress take-all and improve the growth of wheat. Phytopathology 84:940-947.

Ranasinghe, L., Jayawardena, B. and Abeywickrama, K. 2002. Fungicidal activity of essential oils of Cinnamomum zeylanicum (L.) and Syzygium aromaticum (L.) Merr et L.M. Perry against rot and anthracnose pathogens isolated from banana. Lett. Appl. Microbiol. 35:208-211.

Reynolds, J. E. F. 1996. Martindale-The extra pharmacopoeia, $31^{\text {st }}$ edition. Royal Pharmaceutical Society of Great Britain, London, UK.

Ruppel, E. G., Baker, R., Harman, G. E., Hubbard, J. P., Hecker, R. J. and Chet, I. 1983. Field tests of Trichoderma harzianum Rifai aggr. as a biocontrol agent of seedling disease in several crops and Rhizoctonia root rot of sugar beet. Crop Prot. 2:399-408.

Velluti, A., Sanchis, V., Ramos, A. J., Turon, C. and Marin, S. 2004. Impact of essential oil on growth rate, zearalenone and deoxynivalenol production by Fusarium graminearum under different temperature and water activity conditions in maize grain. J. Appl. Microbiol. 96:716-724.

Weindling, R. 1932. Trichoderma lignorum as a parasite of other soil fungi. Phytopathology 22:837-845.

Zaika, L. L. 1988. Spices and herbs: Their antimicrobial activity and its determination. J. Food Safe. 9:97-118. 